\title{
Carbamazepine overdose presenting as a diabetes insipidus - like condition in a child
}

BY MADHURADHAR CHEGONDI, ANDRE RASZYNSKI, BALAGANGADHAR R. TOTAPALLY

\section{Abstract}

Carbamazepine is a commonly used antiepileptic medication. In overdoses it can produce various side effects involving neurological, cardiac, hematological and endocrinal systems. Inappropriate secretion of Anti Diuretic Hormone (ADH) is a well-known complication of carbamazepine toxicity. We are reporting an unusual complication in an adolescent girl with intentional carbamazepine overdose. A sixteen year old female with carbamazepine ingestion presented to our hospital with altered sensorium. On admission she was found to have a very high serum carbamazepine level and metabolic acidosis. In contrast to the possible inappropriate secretion of $\mathrm{ADH}$, as an adverse effect of carbamazepine, her hospital course was complicated with a diabetes insipidus - like condition following treatment with multiple doses of activated charcoal and sodium bicarbonate therapy.

Key words: Carbamazepine, Diabetes Insipidus, activated charcoal, child

\section{Case presentation}


A 16-year-old female, with a history of depression, was brought to our hospital after an intentional overdose of carbamazepine. The patient was found lying by the side of the bed in an unresponsive state. The patient's mother found approximately twenty (200 mg each) carbamazepine pills missing from her step-brother's medication bottle. Emergency Medical Service (EMS) brought the girl to the Emergency Department. Enroute to the hospital, a dose of diphenhydramine was given for dystonic posturing.

The carbamazepine level upon admission was $24.1 \mathrm{mcg} / \mathrm{ml}$ and a computed tomography (CT) scan of the brain was reported normal. Electrocardiogram (ECG) showed borderline QRS widening with possible right bundle branch block. Echocardiogram and cardiac enzymes were normal. She was started on activated charcoal and received multiple doses during her hospital stay. Two hours following admission the child was intubated and placed on a mechanical ventilator for decreased sensorium. Sodium bicarbonate was added to intravenous fluids to correct the metabolic acidosis, with a total intravenous fluid (IVF) sodium content of $190 \mathrm{meq} / \mathrm{l}$, infused at $15 \mathrm{Oml} / \mathrm{hr}$. Carbamazepine levels were monitored every six hours and at six hours after admission the level was $34.5 \mathrm{mcg} / \mathrm{ml}$ and decreased to $4.2 \mathrm{mcg} / \mathrm{ml}$ within three days. Urine toxicology screen was negative. On day two of admission, the patient was polyuric with a urine output of $7 \mathrm{ml} / \mathrm{kg} / \mathrm{hr}$, with negative fluid balance of $3398 \mathrm{ml}$ over a 12-hour period. The possibility of diabetes insipidus was considered and work up was sent. Laboratory data showed hypernatremia (16o mEq /L) and serum hyperosmolality (329 mosm $/ \mathrm{kg}$ ) with a urine osmolality of 459 mosm $/ \mathrm{kg}$ and a urine specific gravity of 1.0oo. Appropriate fluid therapy with $\mathrm{D} 51 / 2 \mathrm{NS}$ was initiated and hypernatremia corrected over the next 48 hours and urine output normalized. The child was discharged from the Pediatric Intensive Care Unit (PICU) with normal electrolyte and acid-base balance, cardiovascular and neurologic condition. Although the fluid balance was positive for the first 24 hours, she never developed hyponatremia. The lowest sodium concentration during her stay was $141 \mathrm{mEq} / \mathrm{L}$. Serial laboratory and fluid balance values are presented in figures 1-3. 


\section{Discussion}

Carbamazepine is a commonly used medication in children with seizure disorders. The Annual Report of the American Association of Poison Control Centers' 2012 data reported a total of 4149 toxic carbamazepine exposures; of them 2162 were isolated ingestions. Over 30 percent of these occurred in children under 19 years of age and 1532 patients received treatment, with one reported death. (1)

Carbamazepine shares structural similarity with tricyclic antidepressants. After oral ingestion, peak plasma concentrations are reached in 4 to 8 hours; it can be delayed up to 24 hours with ingestion of larger doses. (2) Carbamazepine toxicity mainly manifests with neurological and cardiac side effects. $(3,4)$ A life-threatening complication like coma and apnea usually occurs in children with peak levels greater than $28 \mathrm{mcg} / \mathrm{ml}$. (3) Other rare, but serious adverse reactions include agranulocytosis, bone marrow suppression, multiorgan hypersensitivity reactions (DRESS drug rash with eosinophilia and systemic symptoms). (2) It can also produce signs and symptoms of anticholinergic toxidrome. (5)

Other uncommon side effects include hyponatremia due to the syndrome of inappropriate anti diuretic hormone secretion (SIADH) and abnormal thyroid function. $(6,7)$ SIADH is characterized by hyponatremia, low serum osmolality and oliguria. (8) SIADH state, due to carbamazepine, is thought to occur through two mechanisms: by increasing endogenous antidiuretic hormone (ADH) release and by increasing the aquaporin 2 channel expression, resulting in enhanced sensitivity of renal tubules to ADH. $(9,10)$ Carbamazepine is used to treat patients with central or lithium induced diabetes insipidus. $(10,11)$ However, our index patient developed a transient diabetes insipidus (DI) like condition. High serum osmolality, polyuria, hypernatremia, and low urine specific gravity suggest DI but high urine osmolality in our patient negates the diagnosis. The high amount of sodium in the IVF, as sodium bicarbonate, and repeated multiple doses of activated charcoal given to our patient, resulted in hypernatremia. Activated charcoal has sodium benzoate as a preservative and pulls fluid from the body into the gastrointestinal tract resulting in hypernatremia, especially with administration of multiple 


\section{Conclusion}

SIADH is a commonly reported endocrine complication of carbamazepine toxicity in pediatric patients. To the best of our knowledge, there is no association between carbamazepine and diabetes insipidus. Our index case indicates the need for close monitoring of serum sodium levels in children receiving multiple doses of activated charcoal.

\section{References}

1. Moury JB, Spyker DA, Cantilena LR Jr, Bailey JE, Ford M. 2012 Annual Report of the American Association of Poison Control Centers' National Poison Data System (NPDS): 3oth Annual Report. Clin Toxicology 2013;51:949-1229.

2. Brunton LL, JS Lazo, Parker KL. Goodman \& Gilman's The Pharmacological Basis of Therapeutics. 11th Edition., New York: McGraw-Hill; 2012. p. 511-3.

3. Stremski ES, Brady WB, Prasad K, Hennes HA. Pediatric carbamazepine intoxication. Ann Emerg Med 1995;25:624.

4. Starmer CF, Lastra AA, Nesterenko VV, Grant AO. Proarrhythmic response to sodium channel blockade. Theoretical model and numerical experiments. Circulation 1991; 84:1364.

5. Soderstrom J, Murray L, Little M, Daly F FS. Toxicology case of the month: carbamazepine overdose. Emerg Med J 2006;23:869-71.

6. Amelsvoort Van Th, Bakshi R, Devaux CB, Schwabe S. Hyponatremia Associated with Carbamazepine and Oxcarbazepine Therapy: A Review. Epilepsia 1994;35(1):181-8.

7. Aggarwal A, Rastogi N, Mittal H, Chillar N, Patil R. Thyroid hormone levels in children receiving carbamazepine or valproate. Pediatr Neurol Sep 2011;45(3):159-62.

8. Ellison DH, Berl T. Clinical practice. The syndrome of inappropriate antidiuresis. N Engl J Med 2007:356:2064-72.

9. Smith NJ, Espir ML, Baylis PH. Raised plasma arginine vasopressin 
concentration in carbamazepine-induced water intoxication. Br Med J 1977;2:804.

10. Bragança AC, Moyses ZP, Magaldi AJ. Carbamazepine can induce kidney water absorption by increasing aquaporin 2 expression. Nephrol Dial Transplant 2010;25(12):3840-5.

11. Wales JK. Treatment of diabetes insipidus with carbamazepine. Lancet 1975;2:948.

12. Wason S, Baker RC, Carolan P, Seigel R, Druckenbrod RW. Carbamazepine overdose - the effects of multiple dose activated charcoal. Clin Toxicol 1992;30:39-48.

Figure 1. Serial Carbamazepine levels.

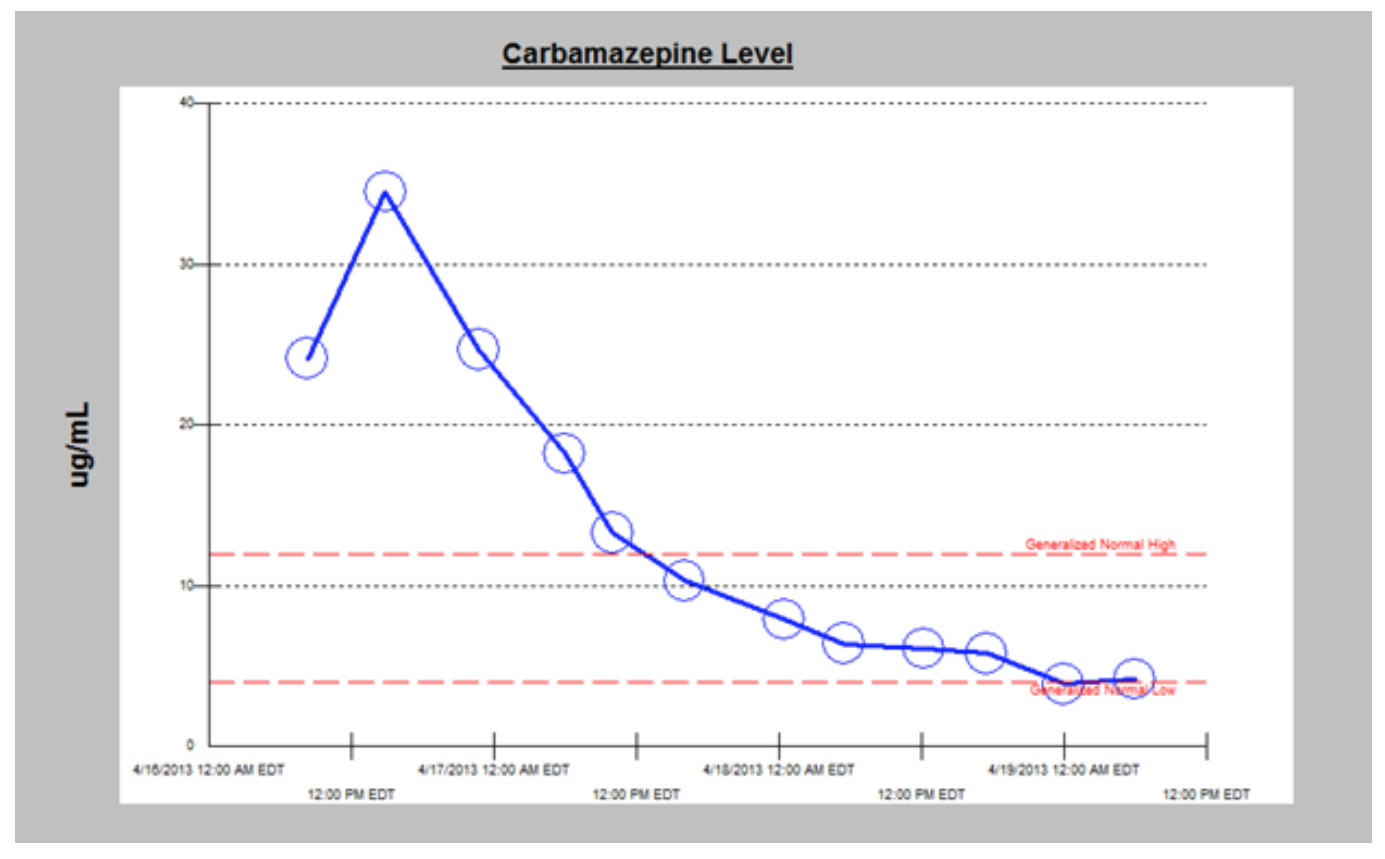

Figure 2. Sodium levels. 


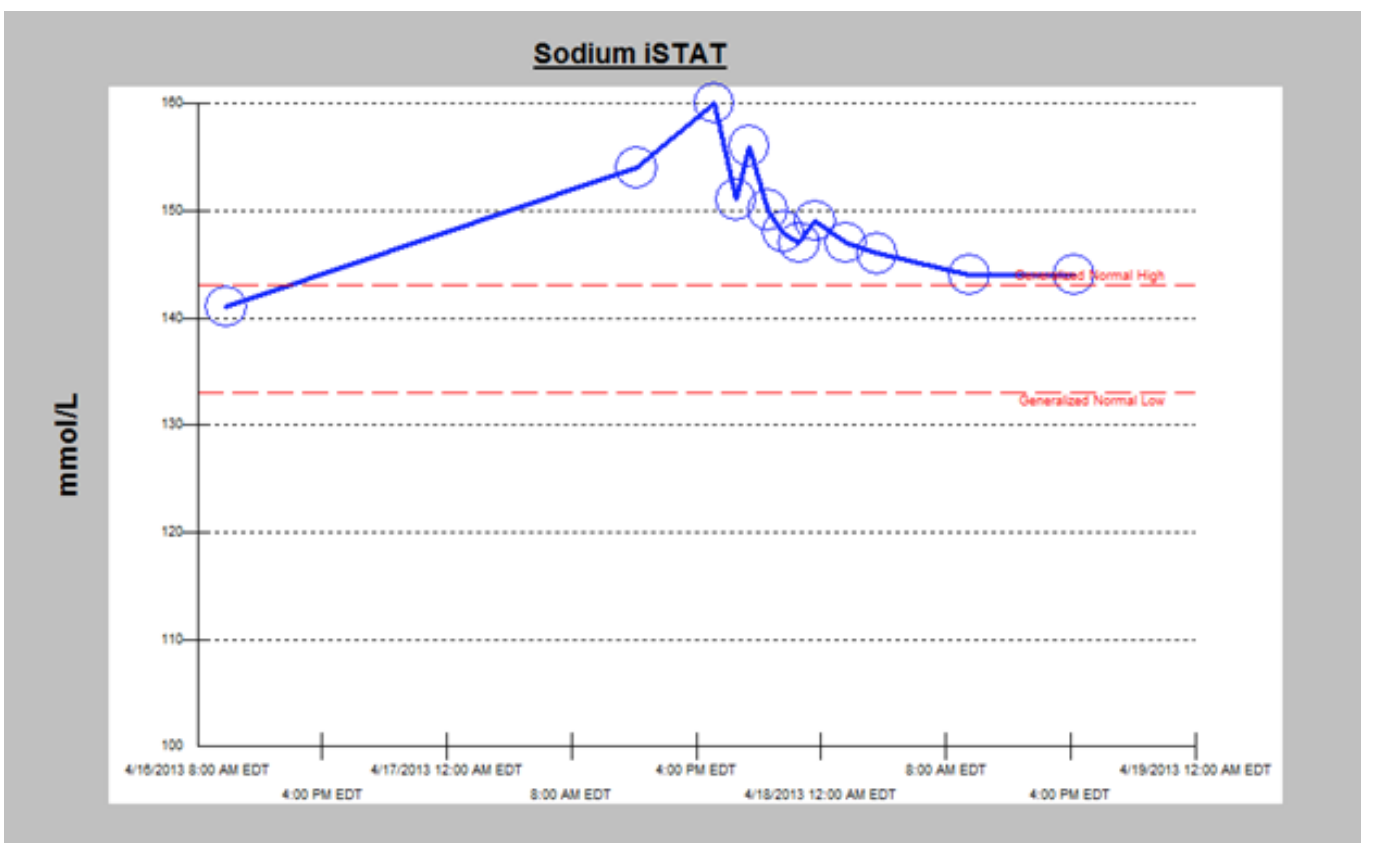

Figure 3. Representing total input \& output (mls).

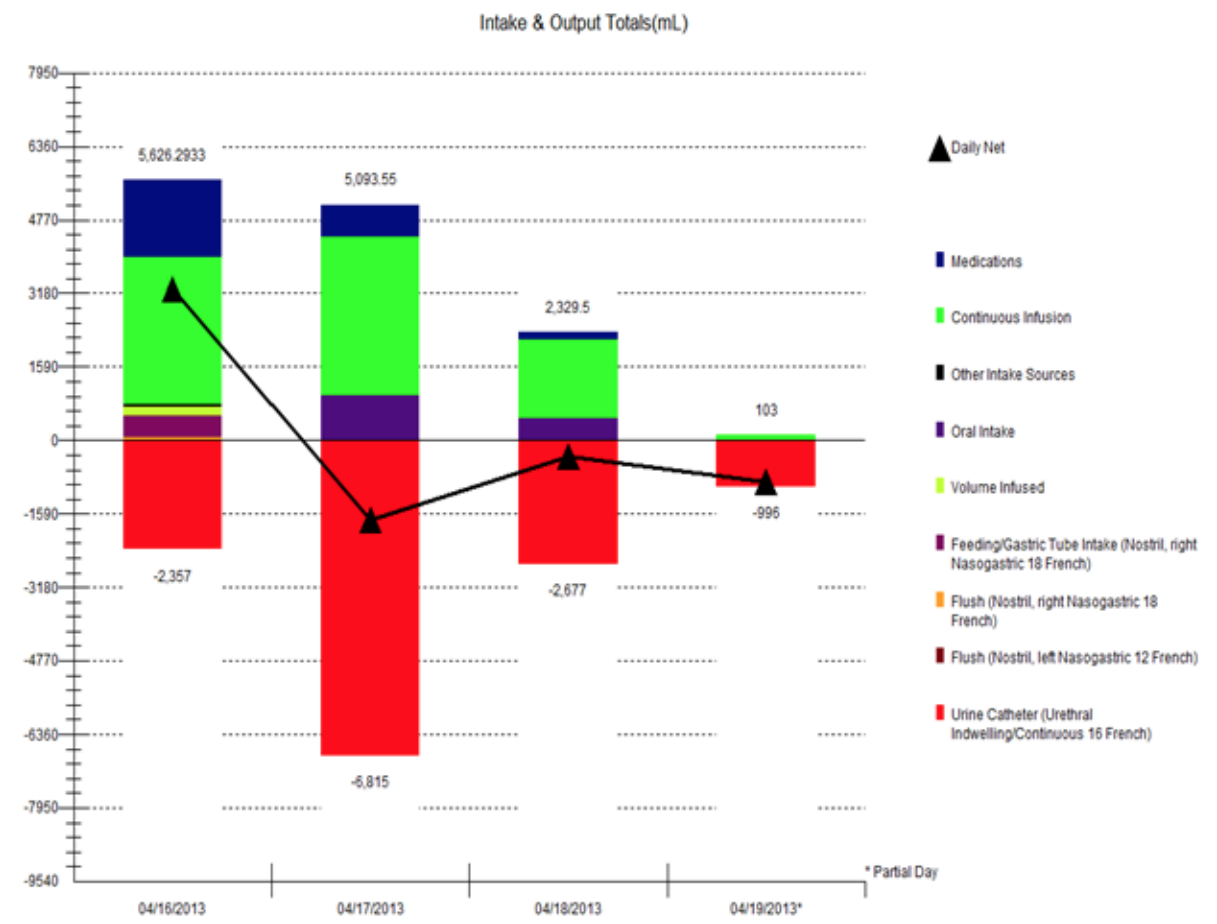

Corresponding author

Madhuradhar Chegondi

Division of Critical Care Medicine

Nemours Children's Hospital

13535 Nemours Parkway, Orlando, FL 32827

Phone: (407) 201-1262

Fax: (407) 567-3880

E-mail: madhuradhar.chegondi@nemours.org; mchegondi@yahoo.com 
Article printed from Signa Vitae: http://www.signavitae.com

URL to article:

http://www.signavitae.com/2015/12/carbamazepine-overdosepresenting-as-a-diabetes-insipidus-like-condition-in-a-child/

Copyright (C) 2015 Signa Vitae. All rights reserved. 